\title{
Current advances in pathogen-plant interaction between Verticillium dahliae and cotton provide new insight in the disease management
}

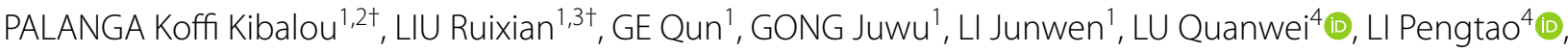 \\ YUAN Youlu ${ }^{1 *}$ (1) and GONG Wankui ${ }^{1 *}$
}

\begin{abstract}
Verticillium wilt is the second serious vascular wilt caused by the phytopathogenic fungus Verticillium dahliae Kleb. It has distributed worldwide, causing serious yield losses and fiber quality reduction in cotton production. The pathogen has developed different mechanisms like the production of cell wall degrading enzymes, activation of virulence genes and protein effectors to succeed in its infection. Cotton plant has also evolved multiple mechanisms in response to the fungus infection, including a strong production of lignin and callose deposition to strengthen the cell wall, burst of reactive oxygen species, accumulation of defene hormones, expression of defense-related genes, and target-directed strategies like cross-kingdom RNAi for specific virulent gene silencing. This review summarizes the recent progress made over the past two decades in understanding the interactions between cotton plant and the pathogen Verticillium dahliae during the infection process. The review also discusses the achievements in the control practices of cotton verticillium wilt in recent years, including cultivation practices, biological control, and molecular breeding strategies. These studies reveal that effective management strategies are needed to control the disease, while cultural practices and biological control approaches show promising results in the future. Furthermore, the biological control approaches developed in recent years, including antagonistic fungi, endophytic bacteria, and host induced gene silencing strategies provide efficient choices for integrated disease management.
\end{abstract}

Keywords: Upland cotton, Verticillium wilt, Plant-pathogen interaction, Disease management

\section{Introduction}

Verticillium wilt $(\mathrm{VW})$ is one of the most devastating fungal diseases in cotton-growing areas across the world and causes severe yield loss and fiber quality reduction. Its principal causal agent is a soil-borne hemibiotrophic filamentous fungus Verticillium dahlia Kleb that causes

\footnotetext{
*Correspondence: yuanyoulu@caas.cn; gongwankui@caas.cn

${ }^{\dagger}$ Palanga KK and Liu RX contributed equally to the work

${ }^{1}$ State Key Laboratory of Cotton Biology, Institute of Cotton Research, Chinese Academy of Agricultural Sciences, Anyang 455000, Henan, China

Full list of author information is available at the end of the article
}

vascular wilt disease in a wide range of important crops (Fradin and Thomma 2006). In China, the disease was introduced along with the seed import of the US cultivars in the 1930s and spread across the main cotton planting areas in the 1970s (Li et al. 2017b). It became a serious issue after the early 1980s in China in the major cotton planting regions of the Yellow River basin and the Yangtze River basin. As being estimated from 2009 and 2010, more than $50 \%$ of the cotton-growing area in China (2.02 to 2.67 million hectares) was affected by VW disease (Zhang et al. 2013). The disease causes substantial loss of cotton yield worldwide (Karademir et al. 2012; Shi et al. original author(s) and the source, provide a link to the Creative Commons licence, and indicate if changes were made. The images or other third party material in this article are included in the article's Creative Commons licence, unless indicated otherwise in a credit line to the material. If material is not included in the article's Creative Commons licence and your intended use is not permitted by statutory regulation or exceeds the permitted use, you will need to obtain permission directly from the copyright holder. To view a copy of this licence, visit http://creativecommons.org/licenses/by/4.0/. 
2016; Tzeng and De Vay 1985; Zhang et al. 2014). Several factors including high population densities of microsclerotia in the soil, low temperature, excessive irrigation, and low seeding rate contribute to the disease severity (Paplomatas 1992). Besides, as a soil-borne pathogen, $V$. dahliae cannot be targeted specifically by any of the current fungicides (Daayf 2015) as opposed to foliar fungal pathogens which can be managed with repeated fungicide applications. These facts, combined with other factors including the effects of global changes in climate and environment, long-term continuous cropping of cotton, and frequent introductions of new cotton varieties from different regions, have expected the severity of cotton VW to continue in the foreseeable future (Guo et al. 2016).

$V$. dahliae isolates have been classified as defoliating or non-defoliating pathotypes based on the symptoms observed on inoculated plants. Defoliating pathotype causes complete defoliation of the cotton plant while the non-defoliating pathotype causes wilting with less defoliation (Schnathorst and Mathre 1966; Temple et al. 1973; Tzeng and De Vay 1985). However, in tomato and lettuce, Verticillium strains have been classified in race 1 and race 2 based on the responses of the host plants after the pathogen infects. Race 1 isolates are characterized by the presence of a gene that encodes a virulence factor (Ave1) whereas race 2 isolates lack Ave 1 factor. A recent study of $317 \mathrm{~V}$. dahliae isolates from China, Israel, Turkey, and the United States, with the strains from tomato and lettuce classified as race 1 and race 2 as controls, suggested that in cotton $V$. dahliae isolates there presents a race structure similar to that observed in lettuce and tomato. The study showed that $97.2 \%$ of defoliating isolates could be categorized as race 2 , while $90.8 \%$ of non-defoliating isolates could be characterized as race 1 (Hu et al. 2015).

In attempts to control the disease and its impacts on cotton production, several approaches have been adopted in order to understand the genetic bases of the disease and to improve the upland cotton resistance to VW. Those approaches include biological, cultural, genetic, and integrated controls. The objective of this review is to summarize the recent findings in the area of the disease genetic bases and the different control approaches assessed by the researchers over the last decade after a brief review of the disease cycle and the different factors affecting its occurrence and incidence.

\section{The disease cycle and symptoms}

$V$. dahliae is a soil-borne hemibiotrophic filamentous fungus that infects plants through roots and colonizes the vascular system via systemic infection. It grows well on a simple medium containing only sugars and amino acids, which are normally found in root exudates (Inderjit and Weston 2003). Its optimum growth temperature is from 22 to $27{ }^{\circ} \mathrm{C}$ and it survives in the soil debris as dormant microsclerotia as deep as up to $40 \mathrm{~cm}$ below the soil surface (Chohan et al. 2020). The life cycle of this fungus can be divided into dormant, parasitic, and saprophytic phases (Klimes and Dobinson 2006). The dormant phase is characterized as the inhibition of microsclerotia germination of the fungus through microbiostasis or mycostasis present in the soil (Chohan et al. 2020; Fitzell et al. 1980). The density of microsclerotia is generally greatest in the uppermost $10-30 \mathrm{~cm}$ of soil and their germination can be stimulated by root exudates of both host and non-host plants (Fradin and Thomma 2006; Jordan 1971; Mol 1995; Taylor et al. 2005). A microsclerotium maintains multiple germination capacities due to the germinating ability of each cell of a microsclerotium and thus enhances the success of its infection. In favorable conditions, hyphae grow out of the microsclerotia and follow the gradient concentration of nutrients present in the secreted root exudates (Fradin and Thomma 2006). The parasitic phase begins when the fungus penetrates a root of a susceptible plant in the region of elongation (root tip or at the sites of lateral roots formation) (Fitzell et al. 1980) and colonizes the cortex. From the cortex, the hyphae penetrate the xylem vessels where conidia are formed. Vascular colonization occurs as conidia are sucked into the plant along with water and trapped in pit cavities or at vessel end walls, so-called trapping sites, where they germinate and invade adjacent vessel elements to continue the plant colonization. Prolific growth in the xylem vessels results in decreased hydraulic conductance to the above-ground plant parts leading to a condition of water deficit. Leaves and stems are therefore deprived of water and showed symptoms of wilting and foliar chlorosis very soon. The saprophytic phase begins as the infected plant senesces. At this stage, the fungus released microsclerotia into the soil along with the decomposed plant debris (Wei et al. 2015). V. dahliae can persist in soil and crop debris in the forms of mycelia, chlamydospores, microsclerotia for extended periods until a new cycle of infection begins; besides, it can also survive saprophytically on other crops and weeds ( $\mathrm{Li}$ et al. 2017b; Luo et al. 2014). Survival of microsclerotia likely depends on soil conditions and cropping system history (Gudmestad et al. 2007; Wheeler et al. 2012).

In cotton, the initial infection occurs in the early growing season, following the germination of microsclerotia. The cotyledons of infected cotton plants become yellowish and quickly dry out. The symptoms of the disease are fully expressed after the flowering stage although it can be seen on relatively young plants. The foliar symptoms include interveinal chlorosis and necrosis and with the disease progression, stunting and premature defoliation 
may occur. Discoloration of the vascular system can be observed on infected plants. Younger bolls may abscise or become malformed (Wheeler and Woodward 2016). Plants may lose their leaves if infected with a defoliating strain of the fungus. However, VW symptoms vary depending on environmental factors such as photoperiod, light intensity, temperature, soil moisture, irrigation, and other cultural practices (irrigation and cultural practices that encourage rank growth and delayed maturity) (Wheeler et al. 2020).

\section{Interaction between cotton plant and the $V$. dahliae}

When the fungus manages to colonize the plant cell, it penetrates the apoplast where various defense compounds of the plant immune system form an efficient barrier. To overcome the barrier there, phytopathogenic fungi produce enzymes called cell-wall degrading enzymes (CWDEs) which can degrade the cell-wall polymers like cellulose, xylan, and pectin. These enzymes are particularly important for phytopathogenic fungi that do not have specialized penetration structures and all phytopathogenic fungi require them during the late stages of invasion (Juge 2006; Kubicek et al. 2014). When microorganisms infect plants through stomata, wounds, and/ or other natural openings, plants have also developed a surveillance system that detects microbial invasion and activates the defense systems.

The cotton plant confronts a wide variety of phytopathogenic microbes and pests in its whole life cycle. To cope with this diversity of parasites, it has developed multi-defense systems to react to pathogens with a wide variety of inducible responses (Doehlemann and Hemetsberger 2013). Plants usually utilize pattern recognition receptors (PRRs) to sense pathogen-associated molecular patterns (PAMPs) and rapidly activate PAMP-triggered immunity (PTI). PAMPs are special molecules common to a microbial family, such as structural constituents or damage-associated molecular patterns (DAMPs). They respond to the products of cell-wall hydrolysis and degradation catalyzed by hydrolases released by the pathogen or host. This recognition initiates a cascade of signalling events resulting in the induction of a battery of immune responses, including $\mathrm{Ca}^{2+}$ influx, a burst of reactive oxygen species (ROS), accumulation of the defense hormones, expression of defense-related genes, and callose deposition (Yang et al. 2018). In turn, pathogens deploy effectors that contribute to pathogen virulence. Effectors can interfere with the PTI. This results in effectortriggered susceptibility (ETS). As an adaptation, a given effector is 'specifically recognized' by one of the resistant $\mathrm{R}$ proteins of the plant leading to effector-triggered immunity (ETI). ETI is a kind of accelerated and amplified PTI response, resulting in disease resistance and, usually, hypersensitive cell death response (HR) at the infection site (Jones and Dangl 2006).

Plant cells are surrounded by stable cell walls that act as a barrier to prevent the penetration of most microbes. The plant cell wall has a heterogeneous structure containing mainly cellulose microfibrils, hemicelluloses, pectins, lignins, and a small number of structural proteins (Tan et al. 2016).

Among the polymers forming the cell wall, lignin is regarded as a component of the defense response in plants and has been reported to function as a defensive physical/chemical barrier to limit pathogen colonization or restrict pathogen growth. It has been reported that the first phase of plant defense against $V$. dahliae includes a quick production and deposit of lignin in epidermal and cortical cell walls of the root. In this process, with the accumulation of lignin produced in secondary xylem and cellulose avoid chemical and biological degradation, the mechanical strength of the stem is enhanced (Song et al. 2020; Zhang et al. 2014). A study aiming to assess cotton resistant mechanism to VW in 3 varieties, Pima 90-53, Jimian 20, and Han 208 , which represent different levels of resistance to the disease, has shown that 35 days after infection, the cell wall was highly lignified and the vascular was unblocked in the resistant variety Pima 90-53, while moderately lignified and slightly blocked in the tolerant variety Jimian 20, and weakly lignified and seriously blocked in the susceptible variety Han 208. Furthermore, transcriptome analysis has revealed that the transcription level of GhLAC in Jimian 20 was significantly higher than that in Han 208 at any time point of the test indicating that laccase plays an important role in cotton resistance to $V$. dahliae through lignin deposition (Wu et al. 2014). The role of laccase on lignin synthesis was reported in Arabidopsis thaliana where the mutation of AtLAC15, a member of the laccase gene family, affects the decrease of extractable lignin content in Arabidopsis seeds (Liang et al. 2006). Screening of a suppression subtractive hybridization ( $\mathrm{SSH}$ ) library of a resistant cotton cultivar Jimian 20 inoculated with $V$. dahliae revealed that a laccase gene GhLAC15, which was phylogenetically related to AtLAC15, was strongly induced by the pathogen. GhLAC15 is predominantly expressed in the roots and the tolerant variety Jimian 20 accumulated more lignin or enhances a higher degree of lignification than Han 208 does upon V. dahliae infection. Another observation showed that overexpression of GhLAC15 in Arabidopsis not only significantly increased lignin content but also increased the content of xylose and arabinose, which were the principal carbohydrates components of plant cell wall, thus leading to the improved VW resistance in the transgenic lines. 
Moreover, the overexpression of GhALAC15 in transgenic Arabidopsis resulted in less cell wall hydrolysis compared with the wild type (Zhang et al. 2018).

Pectin is a polymer present in plant cell walls and cell lining. It maintains cell wall integrity and cell-cell cohesion. Due to the complexity of its molecules, its degradation requires a wide range of enzymes, such as pectin lyases, pectate disaccharide-lyases, and pectatelyases. Among them, pectatelyase is the most studied one, which has been proved to be the key factor causing virulence of some plant pathogens such as Colletotrichum coccodes and Botrytis cinerea (Ben-Daniel et al. 2012; Kars et al. 2005; Yakoby et al. 2001). Moreover, pectatelyase can act as an elicitor of the plant defense like in the case of the pathosystem potato-Erwinia carotovora where that enzyme induced defense responses against Erwinia soft rot (Ponce de León et al. 2007; Wegener 2002). A secretory pectatelyase VdPEL1 has been identified from the supernatant of $V$. dahliae culture (Yang et al. 2018). It triggers plant immune responses, contributes to the virulence of $V$. dahliae, and has the ability to induce cell death and PAMP, thus triggering immune responses through its enzyme activity in tobacco and cotton.

Chitin, a polysaccharide with particular abundance in fungi, acts as a threat to other organisms (Patel and Goyal 2017). Chitinases are pathogenesis-related proteins capable of degrading the cell wall of pathogenic fungi thus releasing PAMP which are elicitors of defense reactions. Chitin elicitor receptor kinase (CERK1), a PTI-associated gene, recognizes chitin oligosaccharides during plantpathogen interactions (Zhang et al. 2013). In a transcriptome analysis of G. barbadense Pima 90-53 inoculated with $V$. dahliae through full-length cDNA library construction and expressed sequence tags (at different hours post-infection), the identified defense-related genes include CERK1 (Zhang et al. 2013). When the chitins in the pathogen cell wall are recognized in the apoplast, the cotton plant produces proteases including chitinase that degrade chitins while releasing elicitors of defense reaction. It has been demonstrated that in VW sensitive cotton cultivars, chitinase is cleaved by $V$. dahliae secretory serine protease 1 (VdSSEP1), thus overcoming the first layer of plant defense. While in the VW resistant Seaisland cultivar Hai 7124, a secretory protein CRR1 rich in cysteine protects chitinase from degradation. Furthermore, the knockdown of CRR1 in cotton plants resulted in higher susceptibility to the infection while its overexpression increased the plant resistance. It has also been observed that the knockout of VdSSEP1 in $V$. dahliae destroyed the pathogenicity of this fungus demonstrating the major role of those two proteins in the interactions between cotton plant and $V$. dahliae (Han et al. 2019).
The ROS that cotton plants produce in response to $V$. dahliae infection consists essentially of superoxide radical $\left(\mathrm{O}_{2}{ }^{-}\right)$, hydroxyl radical $(\mathrm{OH})$, and hydrogen peroxide $\left(\mathrm{H}_{2} \mathrm{O}_{2}\right)$. They are naturally generated by the electron transport chain in mitochondria and chloroplasts, and by membrane oxidases during the process of normal plant development. However, a rapid and localized increase in their production is often detected following the attack by phytopathogenic agents, a phenomenon commonly referred to as "oxidative burst". The content of ROS in plant cells exceeding the threshold may seriously threaten essential cellular entities causing dysfunctions (Foyer and Noctor 2005; Gill and Tuteja 2010). Plants possess antioxidative enzymes, including superoxide dismutase (SOD), catalase (CAT), ascorbate peroxidase (APX), polyphenol oxidase (PPO), glutathione reductase, and other molecules like flavonoids, ascorbate, glutathione, proline, phenolics, tocopherols, and carotenoids, to prevent the oxidative burst caused by the accumulation of ROS generated by pathogen infection (Foyer and Noctor 2005). On the other hand, when accumulated in adequate concentration, ROS can directly kill the pathogen or modulate the major signalling molecules such as MAP kinases, transcription factors, and apoptosis, leading to hypersensitive response, systemic acquired resistance, and cell-wall strengthening of the cotton plant (Tripathy and Oelmüller 2012; Vellosillo et al. 2010). A recent study has identified a total of 49 proteins differentially expressed in cotton root apoplast upon $V$. dahliae infection (Li et al. 2016). Those proteins are mainly ROSrelated, among which a thioredoxin GbNRX1 has been well characterised. GbNRX1 is a member of the nucleoredoxin (NRX) family proteins. The study has shown that silencing of GbNRX1 results in defective dissipation of apoplastic ROS, which led to higher ROS accumulation in the protoplasts and a reduced wilt resistance of the concerned plants, indicating the crucial role of GbNRX1 in ROS regulating plant disease resistance after fungus infection (Li et al. 2016).

More recently, a gene GbaNA1 coding for a nucleotidebinding site leucine-rich repeat (NBS-LRR) protein has been identified in the G. barbadens cultivar Hai 7124 as an important component of the resistance to $V$. dahliae isolate $V d 991$ given that silencing of GbaNA1 altered the resistance of G. barbadense to the fungus. While the $G$. hirsutum accessions that carry a non-functional GbaNA1 orthologue, caused by a premature peptide truncation, they do not possess resistance to $V d 991$ (Li et al. 2018a). Further study of GbaNA1 has shown that ROS activation and ethylene signalling pathway were critical for GbaNA1-mediated resistance against $V$. dahliae (Li et al. 2018b). 
Some genes playing key roles in $V$. dahliae pathogenicity have been identified using host-induced gene silencing (HIGS) (Ghag 2017). Zhang et al. (2016a) were the first to report the utilization of HIGS to induce gene silencing in cotton $V$. dahliae. By using $V$. dahliae hygrophobins 1 gene (VdH1) Knockout mutant to infect cotton plants, they have noticed that the $V d a \Delta v d h 1$ mutant exhibited significantly delayed and reduced induction of symptoms in cotton compared with the WT Vd592 strain. Moreover, $V$. dahliae grow from the infected transgenic cotton line lacked or exhibited reduced development of melanized microsclerotia, showing that $V d H 1$ plays a crucial role in the microsclerotia production. More recently, $\mathrm{Xu}$ et al. (2018) have identified regulators of $G$ protein signalling gene in $V$. dahliae (VdRGS1) as a crucial gene in the fungi pathogenicity. $V d R G S$ genes code for a family of regulators of heterotrimeric guanine nucleotide-binding protein ( $G$ protein) signaling which function by sensing extracellular signals and integrating them into the fungus intrinsic signal transduction pathways. Among the eight identified VdRGS genes, VdRGS1 had the highest expression level and was the most significantly induced when VD8 spores were treated with cotton roots. VdRGS1 deletion mutants developed dumbbell-shaped hyphae, produce a significantly lower quantity of spores, and microsclerotia with lighter color compared with the WT. Furthermore, when inoculated with the VdRGS1 HIGSmutant, cotton seedlings showed fewer leaves yellowing phenotypes compared with the control. All those observations indicate that VdRGS1 gene plays a crucial role in $V$. dahliae spore production, hyphal development, microsclerotia formation, and pathogenicity. Two other genes VdILV2 and VdILV6, which are homologues of ILV2 and ILV6 identified in Saccharomyces cerevisiae, have been identified as key factors of the $V$. dahliae Vd991 strain. ILV2 and ILV6 code for the catalytic and the regulatory subunits of the Acetolactate-synthase respectively, both of which are required for fungal pathogenicity and involved in conidial morphogenesis and branched-chain amino acids biosynthesis in Magnaporthe oryzae and Fusarium graminearum (Du et al. 2013; Liu et al. 2015). Acetolactate-synthase is an enzyme that catalyzes the first step of the synthesis of the branch-chain amino acid (BCAA) in many organisms including plants and fungi. Suppression of VdILV2 or VdILV6 in the strong pathogenic isolate Vd991 through HIGS has drastically reduced $V$. dahliae pathogenicity (Wei et al. 2020).

Small non-coding RNAs (sRNAs) can be expressed in a tissue-specific or stage-specific manner and can be transmitted over short or long distances leading to sequencespecific silencing of a target gene in cells of a well-defined region or throughout the entire plant (Mermigka et al. 2016). Studies have demonstrated that sRNAs can be also transmitted in bi-directional exchanges between plants and their parasites, thus providing a basis for crosskingdom RNAi (ck-RNAi) as a plant defense mechanism (Schaefer et al. 2020). It has been demonstrated that $V$. dahliae recovered from cotton exhibited a large amount of small RNAs that cannot be mapped to Verticillium genome but were identical to the sequence of some cotton miRNA (Zhang et al. 2016a, b). Four microRNAs (miR166, miR167, miR156, and miR159) were readily detectable in $V$. dahliae recovered from infected cotton plants, but undetectable in V592 cultured in vitro without prior cotton colonization. The author concluded that in response to $V$. dahliae infection, cotton plants synthesize these miRNAs and export them to the fungal hyphae for specific silencing. Further analyses have revealed that two $V$. dahliae genes encoding a $\mathrm{Ca}^{2+}$-dependent cysteine protease $(\mathrm{Clp}-1)$ and an isotrichodermin $\mathrm{C}-15$ hydroxylase $(\mathrm{HiC}-15)$, targeted by miR166 and miR159, respectively, are both essential for fungal virulence. $V$. dahliae strains expressing either $\mathrm{Clp}-1$ or $\mathrm{HiC}-15$ rendered resistance to the respective miRNA drastically enhance their virulence in cotton plants. Thus, these findings provide a novel defense strategy of a cotton plant by exporting specific miRNAs to direct specific gene silencing in fungal pathogen to reduce its pathogenicity (Zhang et al. 2016b). Some of the major genes identified from cotton and $V$. dahliae in recent years that play a role in the cotton- $V$. dahliae interaction are listed in Tables 1 and 2 , respectively.

\section{Verticillium wilt management in cotton}

VW management is a challenging issue. Several factors including high population densities of microsclerotia in the soil, low air temperature, excessive irrigation, and low seeding rate contribute to occurrence, development, and seriousness of the disease (Paplomatas 1992). Furthermore, most plants are asymptomatic at the initial stage of infection which makes it difficult to predict the time and severity of the disease and to determine the time to initiate measurement of control. An integrated approach (combination of cultural, chemical, biological, and genetic control) is often used to minimize the losses caused by the wilt.

\section{Cultivation practices}

Among the cultural methods, tarping of moist soil with transparent ethylene plastic during the summer months was proved effective in reducing soil population density of the pathogen and in increasing cotton yields. Indeed, soil heating at sublethal temperatures impaired the ability of $V$. dahliae to penetrate the plant and cause the disease (Pullman et al. 1981). Crop rotation is another way to reduce VW symptoms. An experiment aiming 
Table 1 Newly identified cotton genes playing a role in VW resistance

\begin{tabular}{|c|c|c|c|c|}
\hline Genes & Predominant location & Mechanisms of action & Impact on resistance/susceptibility & References \\
\hline GhLAC15 & Cotton roots cell wall & $\begin{array}{l}\text { Increase the level of lignin, arabinose, and } \\
\text { xylose of the cell wall }\end{array}$ & $\begin{array}{l}\text { Plays a significant role in the resistance of } \\
\text { cotton to the defoliating strains Vd991 and } \\
\text { Vd-gfp77 }\end{array}$ & Zhang et al. (2018) \\
\hline CERK1 & Stem and roots & Chitin elicitor signaling (Perception of PAMP) & $\begin{array}{l}\text { Induce defense responses upon recognition } \\
\text { of fungi chitin oligosaccharides }\end{array}$ & Zhang et al. (2013) \\
\hline CRR1 & Cotton roots & $\begin{array}{l}\text { Binds to chitinase gene Chi } 228 \text { preventing it } \\
\text { from degradation by VdSSEP1 }\end{array}$ & $\begin{array}{l}\text { Involved in resistance against } V \text {. dahliae and a } \\
\text { wide range of pathogenic fungi }\end{array}$ & Han et al. (2019) \\
\hline GbNRX1 & Cotton roots apoplast & $\begin{array}{l}\text { Antioxidant, regulates the ROS level in the } \\
\text { apoplast }\end{array}$ & Involved in the apoplastic immune response & Li et al. (2016) \\
\hline GbaNA1 & Cell nucleus & $\begin{array}{l}\text { Encodes an NB-LRR protein, an R protein } \\
\text { involved in resistance to } \mathrm{VW}\end{array}$ & $\begin{array}{l}\text { Involved in ROS activation and ethylene } \\
\text { signalling pathway }\end{array}$ & Li et al. (2018a) \\
\hline
\end{tabular}

Table 2 Newly identified $V$. dahliae genes playing a role in the fungi virulence and pathogenicity

\begin{tabular}{|c|c|c|c|c|c|}
\hline Genes & Functional annotations & Mutations/silencing & Virulence mechanisms & Strains & References \\
\hline VdPEL 1 & Pectate Lyase & Compromised virulence of $\mathrm{V}$. dahliae & Cell wall degradation & Vd991 & Yang et al. (2018) \\
\hline VdSSEP1 & Secretory Ser Protease & Compromised full virulence of $V$. dahliae & Degrade cotton chitinase & Vd991 & Han et al. (2019) \\
\hline $\mathrm{VdH1}$ & Class II Hydrophobin & Reduced the virulence & $\begin{array}{l}\text { Involved in the produc- } \\
\text { tion of melanized } \\
\text { microsclerotia }\end{array}$ & V592 & Zhang et al. (2016a) \\
\hline VdRGS1 & $\begin{array}{l}\text { Heterotrimeric guanine nucleotide- } \\
\text { binding protein }\end{array}$ & $\begin{array}{l}\text { Production of abnormally shaped } \\
\text { hyphae, reduced quantities of spores } \\
\text { and light color microsclerotia, }\end{array}$ & $\begin{array}{l}\text { Spore production, hyphal } \\
\text { development, micro- } \\
\text { sclerotia formation, and } \\
\text { pathogenicity }\end{array}$ & VD8 & Xu et al. (2018) \\
\hline VdILV2 & $\begin{array}{l}\text { Catalytic subunit of acetolactate- } \\
\text { synthase }\end{array}$ & \multirow{2}{*}{$\begin{array}{l}\text { Reduced accumulation of micro- } \\
\text { sclerotia in cotton plants, reduced } \\
\text { pathogenicity of the fungus }\end{array}$} & \multirow[t]{2}{*}{ Microsclerotia production } & \multirow[t]{2}{*}{ Vd991 } & \multirow[t]{2}{*}{ Wei et al. (2020) } \\
\hline VdILV6 & $\begin{array}{l}\text { Regulatory subunit of acetolactate- } \\
\text { synthase }\end{array}$ & & & & \\
\hline Clp-1 & $\mathrm{Ca}^{2+}$-dependent cysteine protease & \multirow[t]{2}{*}{ Reduces the fungi virulence } & Microsclerotia production & \multirow[t]{2}{*}{ V592 } & \multirow[t]{2}{*}{ Zhang et al. (2016a) } \\
\hline $\mathrm{HiC}-15$ & Isotrichodermin C-15 hydroxylase & & Normal hyphal growth & & \\
\hline
\end{tabular}

to investigate the effect of crop rotation, irrigation and nitrogen rate showed that in a region, where a cottonsorghum rotation of 2-year-cotton-1-year-sorghum is applied, damages caused by VW and the microsclerotia build-up was $10 \%$ lower than that observed in continuous growing cotton (Wheeler et al. 2012). However, most rotations have been unable to eradicate the microsclerotia in a short term (Liu et al. 2021). In the case of continuous cotton planting, even for the susceptible varieties, application of a lower irrigation rate may reduce the damage caused by the disease on crop yield (Wheeler et al. 2020, 2012). Liu et al. (2021) have recommended integrated management strategies composed of using partially resistant cotton cultivars and high seeding rates to reduce the economic loss caused by VW. A close relationship is also observed between the resistance of cotton to VW and the availability of $\mathrm{K}$ in soil. Application of $\mathrm{K}$ fertilizer can reduce both the incidence and the severity of VW of cotton in field. It is observed that K application increases the content of $\mathrm{K}$ and total phenolics in the rhizosphere soil but decreases the content of soluble sugar and alanine. The change of rhizosphere soil creates a good microecological environment for the root system, which leads to a reduced number of bacteria, fungi, and total microorganisms in rhizosphere soil, especially the number of $V$. dahliae and therefore to a reduction of the VW disease incidence (Doumbou et al. 2001; Ju et al. 2020).

\section{Biological control Use of endophytic bacteria}

The use of biological control agents has been increasing worldwide, which represents a real alternative to the application of chemical fungicides. Bacterial antagonists are effective in the biological control of several plant diseases through different mechanisms including antibiosis, siderophore production, induced systemic resistance (ISR), lytic enzyme secretion, and hormone production (Abdelshafy Mohamad et al. 2020; Xue et al. 2013). In the case of VW disease, one of the recent approaches is 
rhizobacteria-mediated biological control. Among those rhizobacteria is the soil-borne Pseudomonas spp that colonizes the roots of cotton plants and produces antifungal metabolites (Xue et al. 2013). In addition, Pseudomonas spp can induce disease resistance in the host plant (Walsh et al. 2001). In a study aiming to test the effect of the bacterisation of cotton seeds by Pseudomonas spp on the disease symptoms, cotton growth parameters and yield under VW pressure, four fluorescent Pseudomonas strains (FP22, FP23, FP30, and FP35), which isolated from symptomless cotton plant and weeds in different cotton-growing regions in Turkey and a biocontrol agent Serratia plymuthica (HRO-C48), were selected for a two years field trials after evaluating their ability for in vitro growth inhibition of the highly virulent Verticillium strain VD-11, disease suppression, and growth promotion under greenhouse conditions. The results showed that the four strains as well as HRO-C48 significantly reduced VW symptoms of both wilt-susceptible (Sayar 314) and wilt-tolerant cotton (Accala Maxxa) cultivars under greenhouse conditions. The reduction of AUDPC (Area under disease severity index progress curve) by the seed bacterisation with FP22, FP23, FP30, FP35, and HROC48 compared with non-bacterized control ranged from $39.2 \%$ to $50.9 \%$ and $22.1 \%$ to $36.8 \%$ in trials done in 2005 and 2006, respectively. Measured growth parameters (plant height, number of nodes on the main stem, and NAWF-nodes above white flower) differed significantly between the control and the treated plants with higher values obtained with the latter ones. In the 2005 field trial, the increase of seed cotton yield by the treatment with the four Pseudomonas strains and HRO-C48 ranged from $13.1 \%$ to $22.3 \%$ in Sayar 314 and $4.2 \%$ to $12.8 \%$ in Acala Maxxa (Erdogan and Benlioglu 2010). Those results suggested that bacteriasation of cotton seed treatment with Pseudomonas spp. and the known Serratiaplymuthica strains could not only be used to control $V$. dahliae infection but also to improve growth parameters of cotton in fields. Another study aiming to assess the effectiveness of strains P. fluorescens and Bacillus spp isolated from different rhizospheric soils and plant roots in the Iranian cotton fields has revealed that, although strains of the two bacteria can significantly reduce the disease symptoms, $P$. fluorescens strains were more effective compared with Bacillus ones (Mansoori et al. 2013).

Most biocontrol approaches of plant diseases are based on a single biocontrol agent, but practically, application of a single endophyte may lead to a sharp decline in its density in different plant growth stages, resulting in insufficient control of VW. Therefore, the combination of dominant endophytic antagonists isolated from different growth stages of upland cotton for continuous control of VW appears more promising for the disease control effectiveness. When three dominant antagonistic endophytic bacterium strains, Paenibacillus xylanilyticus YUPP-1, Paenibacillus polymyxa YUPP-8, and Bacillus subtilis YUPP-2, isolated from cotton of a susceptible cotton cultivar Eza No. 11 at seedling, squaring, and bollsetting stages, respectively, were applied to cotton plant at 2-leaf stage for VW control assays, the results showed that the combined application of three strains had better effect than individual applications (Yang et al. 2013). Similar results were also reported on wheat (Duffy et al. 1996), tomato (Cotxarrera et al. 2002), and cucumber (Trillas et al. 2006) while combining a biocontrol agent with organic amendment or another biocontrol agent (strains from the same species or another bacterial or fungal antagonist) in suppression of disease symptoms in plants. Application of a novel bioorganic fertilizer (BOF), which is composed of a mixture of rapeseed meals hydrolyzed by microbial enzymes and pig manure compost and antagonistic Bacillus subtilis strain $\mathrm{HJ} 5$, could significantly reduce VW symptoms of cotton seedlings and the number of $V$. dahliae colonies per unit area in cotton rhizosphere compared with the control (Li et al. 2013). The number of B. subtilis HJ5 cells on the root surface reached a peak of approximate $10^{7} \mathrm{cfu}$ (colony-forming units) per gram of roots three days after cotton seedlings were exposed to the bacteria, suggesting that the colonization of B. subtilis HJ5 on cotton roots is one of the mechanisms to protect cotton plants from fungal infection (Li et al. 2013).

Actinomycetes can also be used in the biological control of VW disease. Actinomycetes are an important group of gram-positive, filamentous bacteria, which represent a high proportion of soil microbial biomass and play an important role in the rhizosphere ecosystem. They can produce a wide variety of antibiotics and extracellular enzymes. Several actinomycete strains have been found to protect plants from diseases (Doumbou et al. 2001). Four actinomycete isolates, identified as Streptomyces cyaneofuscatus, S. kanamyceticu, S. rochei, and S. flavotricin were sceened among 712 actinomycete isolates based on their ability to efficiently inhibit the growth and conidia production of $V$. dahliae in vitro in a screening study (Xue et al. 2013). The four isolates produced extracellular fungal cell-wall degrading enzymes, including chitinase, $\beta$-1,3-glucosidase, cellulase, and protease when the cell wall of $V$. dahliae was the exclusive carbon source. Microscopic observation showed that the hyphae of the four isolates coiled around the fungal hyphae at the site where the fungal cell wall was lysed. In the following greenhouse study, the biocontrol efficacy of the four isolates against VW of cotton ranged from $18.7 \%$ to $65.8 \%$. In addition, in a field study of VW, when the powdered biocontrol agent was applied either as a seed coating 
agent (biocontrol efficacy 13.5\% 48.0\%) or inoculated in soil (biocontrol efficacy 17.8 51.4\%), the isolates successfully colonized to the cotton rhizosphere. Given their results, the authors concluded that the powdered biocontrol agent, which contains living Streptomyces, had great commercial potential as a biofungicide to control cotton VW. However, as rhizosphere bacteria, actinomycetes showed some differences in their VW-resistant efficacies in field and in greenhouse experiments. In a greenhouse, the control efficacy of actinomyetes was significantly correlated with their antagonistic activities against $V$. dahliae (inhibition activity and cell wall degrading enzyme activity), while in field, the biocontrol efficacy was significantly correlated with their colonization capacities in the cotton rhizosphere. These facts highlight the importance of the colonization capacity of actinomycetes in the rhizosphere and their competitive capacity with the existing rhizosphere microfauna for their successful application as biocontrol agents in the fields (Xue et al. 2013). Applying each of the four Streptomyces species as powdered agents into the soil at sowing time has also shown effective to promote growth, induce disease resistance and reduce disease symptoms in cotton plants treated with VD-toxin, a glycoprotein with toxic and wilting effect on a cotton plant, secreted by $V$. dahliae. The actinomycetes also preserve the physiological functions of plants, such as photosynthesis, root activities (nutrient and water uptake), and reduce the accumulation of MDA, which is an indicator of the membrane lipid peroxidation in the process of cellular senescence or stress, by enhancing the activities of defense-related enzyme and inducing the synthesis of antimicrobial phytoalexins and lignin in cotton (Xue et al. 2016).

Another strain of actinobacteria that can be used as Verticillium wilt biocontrol agent is $P$. polymyxa, formerly known as Bacillus polymyxa, which is a grampositive, rod-shaped, and endospore-forming bacterium. It produces two types of peptide antibiotics against bacteria and a series of LI-F antibiotics, various analogs of fusaricidins, against fungi, gram-positive bacteria, and actinomycetes (Lal and Tabacchioni 2009). In a screening of microorganisms antagonistic to $V$. dahliae from soils of different regions in China, a total of five P. polymyxa strains have been identified, among which strain ShX301 showed the highest antagonistic activity against spore germination and mycelial growth of $V$. dahliae (Zhang et al. 2018). ShX301 significantly reduced the disease incidence and severity by $71.4 \%$ and $40.3 \%$, respectively, and promoted the growth of cotton seedlings, thus suggesting that it can be used as an effective biocontrol agent and/or a plant growth-promoting agent. However, field assays are still required to fully evaluate its efficiency in controlling VW disease.

\section{Use of antagonistic fungi}

Fungi can also be used as biocontrol agent to reduce or to suppress VW symptoms in cotton. A significant reduction of the disease symptoms was observed on cotton plants grown from seed treated with two different strains of Trichoderma virens, G-4 and P, in a greenhouse experiment. In that experiment, $V$. dahliae was stem-inoculated to avoid direct contact between the two fungi. Therefore, the reduction of the VW symptoms in cotton plants was most probably due to the induced resistance by $T$. virens rather than a direct antagonism between the two. The idea that antagonistic rhizospheric fungi be used as plant resistance inducers could be traced back to the work in mid-1990s, which provides evidences that tomato plants grown in the presence of Pythium oligandrum had increased resistance against the attack of Fusarium oxysporum f. sp. radices lycopersici. Their work showed that the beneficial effect of $P$. oligandrum in repressing the pathogen growth and development relies on strong antagonistic activity associated with induction of structural and biochemical barriers in host tissues (Benhamou et al. 1997). Four endophytic fungi namely Penicillium simplicissimum, Leptosphaeria sp, Talaromyces flavus, Acremonium sp. were tested for their effect against the defoliating $V$. dahliae strain Vd080 by Yuan et al. (2017). Under greenhouse condition, the symptoms of VW on endophyte-treated seedlings were not only alleviated but also delayed for 2 to 3 days. Although all of the four endophytic isolates exhibited significant biocontrol efficacy against VW on cotton, Penicillium simplicissimum and Acremonium sp. provided better protection to cotton plants in the disease nursery while Penicillium simplicissimum and Leptosphaeriasp provided better protection at the early squaring stage. Unfortunately, the endophytic fungi no longer provided any protection to cotton plants after the late squaring stage. The authors attributed this fact to the gradual dilution of the colonized endophytes and the competition with the omnipresent microbial flora in soil. Furthermore, the transcript level of PAL, $\mathrm{PPO}$, and POD were significantly higher in plants treated with Penicillium simplicissimum compared with the control. PAL, POD and PPO are reckoned as important component of plant defense mechanism and play a significant role in the ROS regulation.

A cross-protection strategy, in which the use of nonpathogenic or weak virulent isolates of Verticillium to protect the host from infection of virulent isolates and thus reduce the severity of VW, is also suggested. Cross-protection, also known as "pre-immunization", is actually a type of induced resistance developed in host plants. Its basis is that preinfection with a low toxic fungus can protect its hosts from the attacks of its closely related pathogenic strains. Cross-protection was ever 
reported in peppermint $V$. dahliae pathosystem, in which the weakly virulent $V$. dahliae and $V$. nigrescens isolates induced peppermint plant resistance to VW caused by $V$. dahliae (Melouk and Horner 1975). It has also been reported in cotton- $V$. dahliae pathosystem. Co-inoculation of CVn-WHg (Gibellulopsis nigrescens strain with lower pathogenicity) or CVd-WHw ( $V$. dahliae strain with lower pathogenicity) with CVd-AYb (a highly virulent $V$. dahliae isolate) significantly reduced symptoms of VW compared with the inoculation of CVd-AYb alone, suggesting that $\mathrm{CVn}-\mathrm{WHg}$ and $\mathrm{CVd}-\mathrm{WHw}$ may protect cotton against $V$. dahliae. The inoculation of $\mathrm{CVn}-\mathrm{WHg}$ or CVd-WHw 4 days prior to $\mathrm{CVd}-\mathrm{AYb}$ appeared to be more effective in reducing VW symptoms than simultaneous co-inoculations. This suggests that competition between the paired microorganisms played a major role in reducing the disease impact, as preinoculation of $\mathrm{CVn}$ WHg or CVd-WHw would give them more time to colonize the potential infection sites of CVd-AYb and thus inhibit the colonization of the latter (Zhu et al. 2013). Another study has shown that when cotton plants are inoculated with $V$. dahliae prior to $V$. nigrescens (weakly pathogen to cotton), they show aggressive wilt symptoms of VW. However, when the plants are inoculated with $V$. nigrescens prior to $V$. dahliae on the same day, they result in low to mild wilt symptoms. Furthermore, when cotton plants are inoculated with $V$. nigrescens four days prior to $V$. dahliae inoculation, $\mathrm{VW}$ is brought under control (Vagelas and Leontopoulos 2015).

\section{Use of Host Induced Gene Silencing (HIGS) strategy}

A relatively new mean to create resistance to VW disease is the host induced gene silencing (HIGS) based on RNA silencing mechanisms. HIGS is an RNAi-based process, in which small RNAs produced in plants silence the genes of the pests or pathogens that attack the plants. Small RNAs can be produced by double stranded RNA (dsRNA), which is induced in transgenic plants or is introduced into plant cells by Agrobacterium tumefaciens or by viruses that replicate through dsRNA. By infecting cotton plants expressing an RNAi construct of $V$. dahliae hygrophobins1 ( $V d H 1$ ) gene driven under the $35 \mathrm{~S}$ promoter with V592 strain, Zhang et al. (2016a) have observed that transgenic cotton exhibited various degrees of resistance to V592 infection with significantly reduced disease grade compared with the controls. Furthermore, disease nursery evaluation had revealed that 100 day after germination, the progression of the disease was prohibited in transgenic lines. These results demonstrated that expressing VdH1i-derived siRNAs in transgenic cotton plants could confer efficient and effective resistance to $V$. dahliae in the entire plant growth period. Another study demonstrated that tobacco rattle virus-mediated
HIGS targeting VdRGS1 in cotton plant could effectively silence VdRGS1 transcripts in invading $V$. dahliae $\mathrm{Vd} 8$ and V991 strains and significantly enhanced the broadspectrum resistance to cotton VW (Xu et al. 2018). These studies confirmed that HIGS of VdRGS1 provided effective control against $V$. dahliae infection, and the developing of stable transgenic lines could obtain durable disease resistance in cotton and in other VW susceptible host crops (Xu et al. 2018).

\section{Molecular breeding for VW resistance Use of resistant varieties}

The most efficient and cost-effective strategy of disease control is the use of resistant cotton cultivars. However, upland cotton, which contributes $90 \%$ of world cotton fiber production, still lacks heritable genetic germplasms immune to $V$. dahliae. Of the four cultivated cotton species (G. hirsutum L., G. barbadense L., G. arboretum L., and G. herbaceum L.), only G. barbadense, known as Seaisland cotton, has a high level of the resistance against VW. So far, resistance from Sea-island cotton has not been successfully transferred into commercial upland cotton (Zhang et al. 2012), even after a long term efforts have been made to breed VW resistance in upland cotton cultivars (Fang et al. 2014). Given the fact that a cultivar with high resistance to VW displays poor performance in fiber yield and quality, the yield or yield components, fiber quality together with foliar symptoms should be integrated in breeding programs as indicators of $\mathrm{VW}$ tolerance.

VW evaluation can be done in a greenhouse or in field under natural infection or both (Palanga et al. 2017; Ning et al. 2013). Greenhouse tests are more favorable because they are performed in controlled conditions, which ensure a high and uniform level of inoculums, thus minimizing the experimental errors. But a resistant genotype identified in the greenhouse should be always tested and confirmed for their responses to $V$. dahliae infection in field conditions before their use in breeding or production (Martinez et al. 2018). Field tests reflect the natural order of infection and can detect resistance on the basis of mature plants under natural conditions, while environmental conditions tend to cause a biased influence on the results. Uniform inoculation and infection is very difficult to accomplish in field tests. Çelik et al. (2019) evaluated 268 upland cotton genotypes that differ in earliness, yield, and fiber quality characteristics from different countries in response to VW disease in growth chamber and field conditions. The screening was done against the defoliating (PYDV6) and non-defoliating (Vd11) pathotypes. Results showed that cultivars behaved differently in response to the nature of the pathogen (defoliating vs non-defoliating) in greenhouse 
experiment. In the field test, plant genotypes responded differently to the disease in their different developmental stages. Their results also suggested that the early maturity genotypes play a key role in cotton yield under disease condition. Another evaluation was conducted in a greenhouse, which collected ten cotton genotypes comprising the most important Turkish commercial cultivars such as BA-119, SG-125, and Nazilli-84-S and some breeding lines available in Turkey, for resistance to VW using the isolate $\mathrm{I} / 22$, a mildly virulent cotton ND pathotype, and $\mathrm{Mn} / 8$, a highly virulent cotton defoliating pathotype. All the important commercial cultivars were susceptible or extremely susceptible to both pathotypes. Only the cultivar Carmen was resistant to the non-defoliating isolate and MaydosYerlisi was resistant to both pathotypes (Göre et al. 2017). In a multiyear trial aiming to evaluate a total of 259 cultivars, Wheeler and Woodward (2016) identified five varieties with low wilting and defoliating symptoms and high yield. All of these cultivars were traced back to Carmen, which in turn is traced back to DP Acala 90. Acala 90 has been previously identified as a good donor to reduce VW and increase cotton boll weight. Resistance of Acala cotton is thought to be derived from Sea-island cotton; however, there has been no report to indicate the introgression of Pima germplasm to Acala cotton and the origin of the resistance (Zhang et al. 2005). These analyses suggest that breeding of new cotton lines resistant to VW can be achieved through application of resistant germplasms.

\section{VW resistance QTLs identification}

The genetic basis of VW is poorly understood due to the environmental factors and others interacting pathogens such as root-knot and reniform nematodes (Abdelraheem et al. 2020). Different modes of heredity have been reported. Studies with the interspecific crosses between highly resistant G. barbadense and susceptible G. hirsutum reported a dominant or partially dominant inheritance of VW resistance, but when it comes to the intraspecific cross of G. hirsutum, its inheritance pattern appeared more complicated and subject to the controversy. Some studies reported a qualitative resistance to VW controlled by a single dominant gene in certain resistant Upland cotton genotypes based on early-segregating populations such as $\mathrm{F}_{2}$ and $\mathrm{BC}_{1}$, while others showed that the resistance to $\mathrm{VW}$ was a quantitative trait (Zhang et al. 2014).

To better understand the inheritance of cotton plant resistance to VW, a lot of studies have used QTL mapping strategy to perform the linkage and association analyses on cotton tetraploid genome ( $\mathrm{Li}$ et al. 2017a; Palanga et al. 2017; Wang et al. 2008; Zhao et al. 2021). It is estimated more than $400 \mathrm{VW}$ resistant QTLs have been identified to distribute almost all the 26 tetraploid cotton chromosomes from linkage analyses based on different mapping populations (Zhang et al. 2020; Zhao et al. 2021). These studies include both linkage study of biparental segregating populations and genome-wide association study (GWAS) of natural populations. The linkage study includes inter-specific populations of chromosomal segment substitute lines (CSSL) between G. barbadense (donor line) and G. hirsutum (recurrent line) (Shi et al. 2016, 2020; Wang et al. 2008; Zhao et al. 2018), and intra-specific recombinant inbred line (RIL) populations of G. hirsutum (Palanga et al. 2017; Zhao et al. 2017, 2021). GWAS to identify VW resistance QTL (Abdelraheem et al. 2020; Li et al. 2017a) overcomes the limitation of linkage analysis which may have to examine hundreds of candidate genes when a QTL confidence interval covers a large distance.

These studies have used a relatively small population (100 200 individuals) with low genome coverage not allowing a high-resolution mapping of VW QTLs, most of which are localized in very large chromosomal regions and are poorly mapped, making it difficult to further apply the mapping results of VW resistance QTLs of interest. To increase the mapping resolution, a multiparent advanced generation inter-cross (MAGIC) population derived from $11 \mathrm{G}$. hirsutum parental lines (Zhang et al. 2020) or strategies integrating multi-analyses (Zhao et al. 2021) are applied for VW resistance QTL detection, allowing fine mapping of VW resistance QTLs and putative genes. These identified QTLs shall be useful for VW resistance improvement in upland cotton in future breeding projects and the candidate genes that are located in the potential QTL regions shall provide insight into understanding the genetic mechanisms of VW resistance in cotton.

\section{Conclusion and perspectives}

A deep understanding of the different mechanisms involved in cotton plant and $V$. dahliae interaction will provide new opportunities to control the disease. In this review, we provide a broader picture of the new insights in the interaction between cotton and $V$. dahliae and in the management strategies of the disease over the last decade. Cotton plants have evolved various mechanisms to cope with VW disease while the fungus has developed a variety of approaches to subvert the defense mechanism of the plant. With the development of molecular biology and technologies like HIGS and discovery of new molecular mechanisms like cross-kingdom RNA interference, a new door is opened for the development of cotton resistant cultivars. Indeed, the discovery of genes playing a key role in the pathogen pathogenicity can lead to the creation of new fungicides. However, the mechanisms 
by which cotton export miRNA to the fungus need more studies for its understanding in order to be used successfully in the fungi management. Besides, the use of biocontrol agents as a mean to control the disease seems also promising, however, most of the biocontrol agent which have shown certain efficiency in the greenhouse conditions failed to produce the same effect in field's conditions due to soil microfauna composition. Therefore, tests in both greenhouse and field are required for the genuine identification of effective biocontrol agents.

\section{Acknowledgements}

The authors acknowledge SciLang for its linguistic assistance during the preparation of this manuscript and those for their valuable comments and suggestions for this article but not are listed as authors.

\section{Authors' contributions}

Palanga KK and Gong WK conceive the idea and wrote the initial draft of the manuscript. Liu RX and Ge Q help to organize and editing the manuscript. Gong JW, Li JW, Lu QW, and Li PT proof-read and revise the manuscript. Yuan $Y L$ and Gong WK contribute to the final editing of the manuscript. All authors read and approved the final manuscript.

\section{Funding}

This work was funded by China Agriculture Research System of MOF and MARA, the Natural Science Foundation of China (32070560, 31471538, and 31371668), Special Project of Fundamental Research Funds for the National Public Welfare Institutions of Institute of Cotton Research of Chinese Academy of Agricultural Sciences (1610162021004), the National Key R\&D Program of China (2017YFD0101603-11, 2016YFD0100500, 2016YFD0101401), the Agricultural Science and Technology Innovation Program for CAAS (CAASASTIP-ICRCAAS), the National High Technology Research and Development Program of China (2012AA101108 and 2009AA101104) and the Central Level of the Scientific Research Institutes for Basic R \& D Special Fund Business (1610162014008).

\section{Availability of data and materials}

Not applicable.

\section{Declarations}

Ethics approval and consent to participate

Not applicable.

\section{Consent for publication}

Not applicable.

\section{Competing interests}

Authors declare that they have no conflict of interest for the publication of the manuscript.

\section{Author details}

${ }^{1}$ State Key Laboratory of Cotton Biology, Institute of Cotton Research, Chinese Academy of Agricultural Sciences, Anyang 455000, Henan, China. ${ }^{2}$ Institut Supérieur Des Métiers de L'Agriculture, Université de Kara (ISMA-UK), PO Box 404, Kara, Togo. ${ }^{3}$ Department of Agronomy/Key Laboratory of Agriculture Biological Technology, Xinjiang Agriculture University, Urumqi 830052, China. ${ }^{4}$ School of Biotechnology and Food Engineering, Anyang Institute of Technology, Anyang 455000, Henan, China.

Received: 4 May 2021 Accepted: 4 August 2021

Published online: 01 September 2021

\section{References}

Abdelraheem A, Elassbli H, Zhu Y, et al. A genome-wide association study uncovers consistent quantitative trait loci for resistance to Verticillium wilt and Fusarium wilt race 4 in the US Upland cotton. Theor Appl Genet. 2020;133(2):563-77. https://doi.org/10.1007/s00122-019-03487-x.

Abdelshafy Mohamad OA, Ma J, Liu Y, et al. Beneficial endophytic bacterial populations associated with medicinal plant Thymus vulgaris alleviate salt stress and confer resistance to Fusarium oxysporum. Front Plant Sci. 2020;11:47. https://doi.org/10.3389/fpls.2020.00047.

Ben-Daniel BH, Bar-Zvi D, Tsror LL. Pectate lyase affects pathogenicity in natural isolates of Colletotrichum coccodes and in pelA gene-disrupted and geneoverexpressing mutant lines. Mol Plant Pathol. 2012;13(2):187-97. https:// doi.org/10.1111/j.1364-3703.2011.00740.x.

Benhamou N, Rey P, Chérif M, et al. Treatment with the mycoparasite Pythium oligandrum triggers induction of defense-related reactions in tomato roots when challenged with Fusarium oxysporum f. sp. radicis-lycopersici. Phytopathology. 1997;87(1):108-22. https://doi.org/10.1094/PHYTO.1997. 87.1.108.

Çelik S, Bardak A, Erdoğan O. Screening of upland cotton genotypes (Gossypium hirsutum L.) against cotton verticillium (Verticillium dahliae Kleb.) Wilt. Bangladesh J Bot. 2019;48(4):1185-92. https://doi.org/10.3329/bjb. v48i4.49074.

Chohan S, Perveen R, Abid M et al. Cotton diseases and their management. In: Ahmad S, Hasanuzzaman M, editors. Cotton Production and Uses: Agronomy, Crop Protection, and Postharvest. Singapore: Springer; 2020. p. 239-70. https://doi.org/10.1007/978-981-15-1472-2_13

Cotxarrera L, Trillas-Gay MI, Steinberg C, et al. Use of sewage sludge compost and Trichoderma asperellum isolates to suppress Fusarium wilt of tomato. Soil Biol Biochem. 2002;34(4):467-76. https://doi.org/10.1016/S00380717(01)00205-X

Daayf F. Verticillium wilts in crop plants: pathogen invasion and host defence responses. Can J Plant Pathol. 2015;37(1):8-20. https://doi.org/10.1080/ 07060661.2014 .989908

Doehlemann G, Hemetsberger C. Apoplastic immunity and its suppression by filamentous plant pathogens. New Phytol. 2013;198(4):1001-16. https:// doi.org/10.1111/nph.12277.

Doumbou CL, Hamby Salove MK, Crawford DL, Beaulieu C. Actinomycetes, promising tools to control plant diseases and to promote plant growth. Phytoprotection. 2001;82(3):85-102. https://doi.org/10.7202/706219ar.

Du Y, Zhang H, Hong L, et al. Acetolactate synthases Mollv2 and Mollv6 are required for infection-related morphogenesis in Magnaporthe oryzae. Mol Plant Pathol. 2013;14(9):870-84. https://doi.org/10.1111/mpp.12053.

Duffy BK, Simon A, Weller DM. Combination of Trichoderma koningii with fluorescent pseudomonads for control of talk-all on wheat. Phytopathology. 1996;86(2):188-94. https://doi.org/10.1094/Phyto-86-188.

Erdogan O, Benlioglu K. Biological control of Verticillium wilt on cotton by the use of fluorescent Pseudomonas spp. under field conditions. Biol Control. 2010;53(1):39-45. https://doi.org/10.1016/j.biocontrol.2009.11.011.

Fang $\mathrm{H}$, Zhou H, Sanogo S, et al. Quantitative trait locus analysis of Verticillium wilt resistance in an introgressed recombinant inbred population of Upland cotton. Mol Breed. 2014;33(3):709-20. https://doi.org/10.1007/ s11032-013-9987-9.

Fitzell R, Evans G, Fahy PC. Studies on the colonization of plant roots by Verticillium dahliae Klebahn with use of immunofluorescent staining. Aust J Bot. 1980;28(3):357-68. https://doi.org/10.1071/BT9800357.

Foyer $\mathrm{CH}$, Noctor G. Redox homeostasis and antioxidant signaling: a metabolic interface between stress perception and physiological responses. Plant Cell. 2005;17(7):1866-75. https://doi.org/10.1105/tpc.105.033589.

Fradin EF, Thomma BPHJ. Physiology and molecular aspects of Verticillium wilt diseases caused by V. dahliae and V. albo-atrum. Mol Plant Pathol. 2006;7(2):71-86. https://doi.org/10.1111/j.1364-3703.2006.00323.x.

Ghag SB. Host induced gene silencing, an emerging science to engineer crop resistance against harmful plant pathogens. Physiol Mol Plant P. 2017;100:242-54. https://doi.org/10.1016/j.pmpp.2017.10.003.

Gill SS, Tuteja N. Reactive oxygen species and antioxidant machinery in abiotic stress tolerance in crop plants. Plant Physiol Biochem. 2010;48(12):90930. https://doi.org/10.1016/j.plaphy.2010.08.016.

Göre ME, Erdoğan O, Altın N. Searching for resistance sources to Verticillium wilt of cotton in seedlings from Gossypium spp. Trop Plant Pathol. 2017;42(1):28-31. https://doi.org/10.1007/s40858-016-0120-6. 
Gudmestad NC, Taylor RJ, Pasche JS. Management of soilborne diseases of potato. Australas Plant Pathol. 2007;36(2):109-15. https://doi.org/10.1071/ AP06091.

Guo X, Cai C, Yuan D, et al. Development and identification of Verticillium wilt-resistant upland cotton accessions by pyramiding QTL related to resistance. J Integr Agric. 2016;15(3):512-20. https://doi.org/10.1016/ S2095-3119(15)61083-8.

Han LB, Li YB, Wang FX, et al. The cotton apoplastic protein CRR1 stabilizes chitinase 28 to facilitate defense against the fungal pathogen Verticillium dahliae. Plant Cell. 2019;31(2):520-36. https://doi.org/10.1105/tpc.18. 00390.

Hu XP, Gurung S, Short DPG, et al. Nondefoliating and defoliating strains from cotton correlate with races 1 and 2 of Verticillium dahliae. Plant Dis. 2015:99(12):1713-20. https://doi.org/10.1094/PDIS-03-15-0261-RE.

Inderjit R, Weston LA. Root exudates: an overview. In: de Kroon H, Visser EJW, editors. Root ecology. Ecological studies (analysis and synthesis), vol. 168. Berlin: Springer; 2003. p. 235-55. https://doi.org/10.1007/978-3-66209784-7_10.

Jones JDG, Dangl JL. The plant immune system. Nature. 2006;444(7117):323-9. https://doi.org/10.1038/nature05286.

Jordan VWL. Estimation of the distribution of Verticillium populations in infected strawberry plants and soil. Plant Path. 1971;20(1):21-4. https:// doi.org/10.1111/j.1365-3059.1971.tb00501.x.

Ju F, Li Y, Zhang X, et al. Effects of potassium application on soil ecological resistance to Verticillium wilt of cotton (Gossypium hirsutum L.). Arch Agron Soil Sci. 2020. https://doi.org/10.1080/03650340.2020.1841173.

Juge N. Plant protein inhibitors of cell wall degrading enzymes. Trends Plant Sci. 2006;11(7):359-67. https://doi.org/10.1016/j.tplants.2006.05.006.

Karademir E, Karademir C, Ekinci R, et al. Effect of Verticillium dahliae Kleb. on cotton yield and fiber technological properties. Int J Plant Prod. 2012:6(4):387-408. https://doi.org/10.1111/j.1365-3180.2012.00940.x.

Kars I, Krooshof GH, Wagemakers L, et al. Necrotizing activity of five Botrytis cinerea endopolygalacturonases produced in Pichia pastoris. Plant J. 2005;43(2):213-25. https://doi.org/10.1111/j.1365-313X.2005.02436.x.

Klimes A, Dobinson KF. A hydrophobin gene, VDH1, is involved in microsclerotial development and spore viability in the plant pathogen Verticillium dahliae. Fungal Genet Biol. 2006;43(4):283-94. https://doi.org/10.1016/j. fgb.2005.12.006.

Kubicek CP, Starr TL, Glass NL. Plant cell wall-degrading enzymes and their secretion in plant-pathogenic fungi. Annu Rev Phytopathol. 2014;52(1):427-51. https://doi.org/10.1146/annur ev-phyto-102313-045831.

Lal S, Tabacchioni S. Ecology and biotechnological potential of Paenibacillus polymyxa: a minireview. Indian J Microbiol. 2009;49(1):2-10. https://doi. org/10.1007/s12088-009-0008-y.

Li NY, Ma XF, Short DPG, et al. The island cotton NBS-LRR gene GbaNA1 confers resistance to the non-race 1 Verticillium dahliae isolate Vd991. Mol Plant Pathol. 2018;19(6):1466-79. https://doi.org/10.1111/mpp.12630.

Li NY, Zhou L, Zhang DD, et al. Heterologous expression of the cotton NBS-LRR gene GbaNA1 enhances Verticillium wilt resistance in Arabidopsis. Front Plant Sci. 2018;9:119. https://doi.org/10.3389/fpls.2018.00119.

Li S, Zhang N, Zhang Z, et al. Antagonist Bacillus subtilis HJ5 controls Verticillium wilt of cotton by root colonization and biofilm formation. Biol Fert Soils. 2013;49(3):295-303. https://doi.org/10.1007/s00374-012-0718-X.

Li T, Ma X, Li N, et al. Genome-wide association study discovered candidate genes of Verticillium wilt resistance in upland cotton (Gossypium hirsutum L.). Plant Biotechnol J. 2017;15(12):1520-32. https://doi.org/10.1111/pbi. 12734.

Li X, Zhang Y, Ding C, et al. Temporal patterns of cotton Fusarium and Verticillium wilt in Jiangsu coastal areas of China. Sci Rep. 2017;7(1):12581. https://doi.org/10.1038/s41598-017-12985-1.

Li YB, Han LB, Wang HY, et al. The thioredoxin GbNRX1 plays a crucial role in homeostasis of apoplastic reactive oxygen species in response to Verticillium dahliae infection in cotton. Plant Physiol. 2016;170(4):2392-406. https://doi.org/10.1104/pp.15.01930.

Liang M, Davis E, Gardner D, et al. Involvement of AtLAC15 in lignin synthesis in seeds and in root elongation of Arabidopsis. Planta. 2006;224(5):1185-96. https://doi.org/10.1007/s00425-006-0300-6.

Liu X, Han Q, Xu J, et al. Acetohydroxyacid synthase Fgllv2 and Fgllv6 are involved in BCAA biosynthesis, mycelial and conidial morphogenesis and full virulence in Fusarium graminearum. Sci Rep. 2015;5(1):16315. https:// doi.org/10.1038/srep16315.

Liu X, Woodward JE, Kelly B, et al. Effects of production practices on temporal disease progress of Verticillium wilt of cotton (Gossypium hirsutum L.) in the Texas High Plains, USA. Crop Prot. 2021;140:105429. https://doi.org/ 10.1016/j.cropro.2020.105429.

Luo X, Xie C, Dong J, et al. Interactions between Verticillium dahliae and its host: vegetative growth, pathogenicity, plant immunity. Appl Microbiol Biotechnol. 2014;98(16):6921-32. https://doi.org/10.1007/ s00253-014-5863-8.

Mansoori M, Heydari A, Hassanzadeh N, et al. Evaluation of Pseudomonas and Bacillus bacterial antagonists for biological control of cotton Verticillium wilt disease. J Plant Prot Res. 2013;2(53):154-7. https://doi.org/10.2478/ jppr-2013-0023.

Martinez G, Abdelraheem A, Darapuneni M, et al. Evaluation of a multi-parent advanced generation inter-cross (MAGIC) introgressed line population for Verticillium wilt resistance in Upland cotton. Euphytica. 2018;214(10):197. https://doi.org/10.1007/s10681-018-2278-0.

Melouk HA, Horner CE. Cross protection in mints by Verticillium nigrescens against V. dahliae. Phytopathology. 1975;65:767-9. https://doi.org/10. 1094/phyto-65-767.

Mermigka G, Verret F, Kalantidis K. RNA silencing movement in plants. J Integr Plant Biol. 2016;58(4):328-42. https://doi.org/10.1111/jipb.12423.

$\mathrm{Mol} \mathrm{L}$. Effect of plant roots on the germination of microsclerotia of Verticillum dahliae. Eur J Plant Pathol. 1995;101(6):679-85. https://doi.org/10.1007/ BF01874872.

Ning $\mathrm{N}$, Zhao $\mathrm{R}$, Chen $\mathrm{H}$, et al. Molecular tagging of a major quantitative trait locus for broad-spectrum resistance to Verticillium wilt in upland cotton cultivar prema. Crop Sci. 2013;53(6):2304-12. https://doi.org/10.2135/ cropsci2012.12.0694.

Palanga KK, Jamshed M, Rashid M, et al. Quantitative trait locus mapping for Verticillium wilt resistance in an upland cotton recombinant inbred line using SNP-based high density genetic map. Front Plant Sci. 2017;8:382. https://doi.org/10.3389/fpls.2017.00382.

Paplomatas EJ. Incidence of Verticillium wilt and yield losses of cotton cultivars (Gossypium hirsutum) based on soil inoculum density of Verticillium dahliae. Phytopathology. 1992;82(12):1417-20. https://doi.org/10.1094/ Phyto-82-1417.

Patel S, Goyal A. Chitin and chitinase: role in pathogenicity, allergenicity and health. Int J Biol Macromol. 2017;97:331-8. https://doi.org/10.1016/j.jibio mac.2017.01.042.

Ponce de León I, Oliver JP, Castro A, et al. Erwinia carotovora elicitors and Botrytis cinerea activate defense responses in Physcomitrella patens. BMC Plant Biol. 2007;7(1):52. https://doi.org/10.1186/1471-2229-7-52.

Pullman GS, DeVay JE, Garber RH, et al. Soil solarization: effects on Verticillium wilt of cotton and soilborne populations of Verticillium dahliae, Pythium spp., Rhizoctonia solani, and Thielaviopsis basicola. Phytopathology. 1981;71(9):954-9. https://doi.org/10.1094/Phyto-71-954.

Schaefer LK, Parlange F, Buchmann G, et al. Cross-kingdom RNAi of pathogen effectors leads to quantitative adult plant resistance in wheat. Front Plant Sci. 2020;11:253. https://doi.org/10.3389/fpls.2020.00253.

Schnathorst WC, Mathre DE. Host range and differentiation of a severe form of Verticillium albo-atrum in cotton. Phytopathology. 1966;56(10):1155-61.

Shi Y, Liu A, Li J, et al. Examining two sets of introgression lines across multiple environments reveals background-independent and stably expressed quantitative trait loci of fiber quality in cotton. Theor Appl Genet. 2020;133(7):2075-93. https://doi.org/10.1007/s00122-020-03578-0.

Shi Y, Zhang B, Liu A, et al. Quantitative trait loci analysis of Verticillium wilt resistance in interspecific backcross populations of Gossypium hirsutum $\times$ Gossypium barbadense. BMC Genom. 2016;17(1):877. https://doi.org/10. 1186/s12864-016-3128-X.

Song R, Li J, Xie C, et al. An overview of the molecular genetics of plant resistance to the Verticillium wilt pathogen Verticillium dahliae. Int J Mol Sci. 2020;21(3):1120. https://doi.org/10.3390/ijms21031120.

Tan MSF, Moore SC, Tabor RF, et al. Attachment of Salmonella strains to a plant cell wall model is modulated by surface characteristics and not by specific carbohydrate interactions. BMC Microbiol. 2016;16(1):212. https:// doi.org/10.1186/s12866-016-0832-2.

Taylor RJ, Pasche JS, Gudmestad NC. Influence of tillage and method of metam sodium application on distribution and survival of Verticillium dahliae in 
the soil and the development of Verticillium wilt of potato. Am J Potato Res. 2005;82(6):451-61. https://doi.org/10.1007/BF02872223.

Temple SH, DeVay JE, Forrester LL. Temperature effects upon development and pathogenicity of defoliating and nondefoliating pathotypes of Verticillium dahliae in leaves of cotton plants. Phytopathology. 1973;63:953-8. https://doi.org/10.1094/Phyto-63-953.

Trillas Ml, Casanova E, Cotxarrera L, et al. Composts from agricultural waste and the Trichoderma asperellum strain T-34 suppress Rhizoctonia solani in cucumber seedlings. Biol Control. 2006;39(1):32-8. https://doi.org/10. 1016/j.biocontrol.2006.05.007.

Tripathy BC, Oelmüller R. Reactive oxygen species generation and signaling in plants. Plant Signal Behav. 2012;7(12):1621-33. https://doi.org/10.4161/ psb.22455.

Tzeng DD, De Vay JE. Physiological responses of Gossypium hirsutum L. to infection by defoliating and nondefoliating pathotypes of Verticillium dahliae Kleb. Mol Plant Pathol. 1985;26(1):57-72. https://doi.org/10.1016/ 0048-4059(85)90030-X.

Vagelas I, Leontopoulos S. Cross-protection of cotton against Verticillium wilt by Verticillium nigrescens. Emir J Food Agric. 2015;27(9):687-91. https:// doi.org/10.9755/ejfa.2015-04-047.

Vellosillo T, Vicente J, Kulasekaran S, et al. Emerging complexity in reactive oxygen species production and signaling during the response of plants to pathogens. Plant Physiol. 2010;154(2):444-8. https://doi.org/10.1104/ pp.110.161273.

Walsh UF, Morrissey JP, O'Gara F. Pseudomonas for biocontrol of phytopathogens: from functional genomics to commercial exploitation. Curr Opin Biotechnol. 2001;12(3):289-95. https://doi.org/10.1016/s0958-1669(00) 00212-3.

Wang HM, Lin ZX, Zhang XL, et al. Mapping and quantitative trait loc analysis of Verticillium wilt resistance genes in cotton. J Integr Plant Biol. 2008:50(2):174-82. https://doi.org/10.1111/j.1744-7909.2007.00612.x.

Wegener CB. Induction of defence responses against Erwinia soft rot by an endogenous pectate lyase in potatoes. Physiol Mol Plant Pathol. 2002;60(2):91-100. https://doi.org/10.1006/pmpp.2002.0377.

Wei C, Qin T, Li Y, et al. Host-induced gene silencing of the acetolactate synthases VdILV2 and VdILV6 confers resistance to Verticillium wilt in cotton (Gossypium hirsutum L.). Biochem Biophys Res Commun 2020:524(2):392-7. https://doi.org/10.1016/j.bbrc.2020.01.126.

Wei F, Shang W, Yang J, et al. Spatial pattern of Verticillium dahliae microsclerotia and cotton plants with wilt symptoms in commercial plantations. PLoS ONE. 2015;10(7):e0132812. https://doi.org/10.1371/journal.pone. 0132812.

Wheeler TA, Bordovsky JP, Keeling JW, et al. The effects of tillage system and irrigation on Verticillium wilt and cotton yield. Crop Prot. 2020;137: 105305. https://doi.org/10.1016/j.cropro.2020.105305.

Wheeler TA, Bordovsky JP, Keeling JW, et al. Effects of crop rotation, cultivar, and irrigation and nitrogen rate on Verticillium wilt in cotton. Plant Dis. 2012;96(7):985-9. https://doi.org/10.1094/PDIS-02-11-0111-RE.

Wheeler TA, Woodward JE. Field assessment of commercial cotton cultivars for Verticillium wilt resistance and yield. Crop Prot. 2016;88:1-6. https://doi. org/10.1016/j.cropro.2016.05.006.

Wu LZ, Wang XF, Zhang Y, et al. Function of acid insoluble lignin and GhLaccase in cotton resistance to Verticillium wilt. Acta Agron Sin. 2014:40(7):115763. https://doi.org/10.3724/SP.J.1006.2014.01157.

Xu J, Wang X, Li Y, et al. Host-induced gene silencing of a regulator of $\mathrm{G}$ protein signalling gene (Vd RGS1) confers resistance to Verticillium wilt in cotton. Plant Biotechnol J. 2018;16(9):1629-43. https://doi.org/10.1111/pbi. 12900.

Xue L, Gu MY, Xu WL, et al. Antagonistic Streptomyces enhances defenserelated responses in cotton for biocontrol of wilt caused by phytotoxin of Verticillium dahliae. Phytoparasitica. 2016;44(2):225-37. https://doi.org/10 1007/s12600-016-0517-2.

Xue L, Xue Q, Chen Q, et al. Isolation and evaluation of rhizosphere actinomycetes with potential application for biocontrol of Verticillium wilt of cotton. Crop Prot. 2013;43:231-40. https://doi.org/10.1016/j.cropro.2012. 10.002.

Yakoby N, Beno-Moualem D, Keen NT, et al. Colletotrichum gloeosporioides pelB is an important virulence factor in avocado fruit-fungus interaction. Mol Plant Microbe Interact. 2001;14(8):988-95. https://doi.org/10.1094/MPMI. 2001.14.8.988.

Yang P, Sun Z, Liu S, et al. Combining antagonistic endophytic bacteria in different growth stages of cotton for control of Verticillium wilt. Crop Prot 2013:47:17-23. https://doi.org/10.1016/j.cropro.2012.12.020.

Yang Y, Zhang Y, Li B, et al. A Verticillium dahliae pectate lyase induces plant immune responses and contributes to virulence. Front Plant Sci. 2018;9:1271. https://doi.org/10.3389/fpls.2018.01271.

Yuan $Y$, Feng $\mathrm{H}$, Wang $\mathrm{L}$, et al. Potential of endophytic fungi isolated from cotton roots for biological control against verticillium wilt disease. PLOS ONE. 2017;12(1): e0170557. https://doi.org/10.1371/journal.pone.0170557.

Zhang F, Li XL, Zhu SJ, et al. Biocontrol potential of Paenibacillus polymyxa against Verticillium dahliae infecting cotton plants. Biol Control. 2018;127:70-7. https://doi.org/10.1016/.j.biocontrol.2018.08.021.

Zhang J, Abdelraheem A, Thyssen GN, et al. Evaluation and genome-wide association study of Verticillium wilt resistance in a MAGIC population derived from intermating of eleven Upland cotton (Gossypium hirsutum) parents. Euphytica. 2020;216(1):9. https://doi.org/10.1007/ s10681-019-2547-6.

Zhang J, Fang H, Zhou H, et al. Genetics, breeding, and marker-assisted selection for Verticillium wilt resistance in cotton. Crop Sci. 2014;54(4):1289303. https://doi.org/10.2135/cropsci2013.08.0550.

Zhang JF, Lu Y, Adragna H, et al. Genetic improvement of New Mexico Acala cotton germplasm and their genetic diversity. Crop Sci. 2005;45(6):236373. https://doi.org/10.2135/cropsci2005.0140.

Zhang J, Sanogo S, Flynn R, et al. Germplasm evaluation and transfer of Verticillium wilt resistance from Pima (Gossypium barbadense) to Upland cotton (G. hirsutum). Euphytica. 2012;187(2):147-60. https://doi.org/10. 1007/s10681-011-0549-0.

Zhang T, Jin Y, Zhao JH, et al. Host-induced gene silencing of the target gene in fungal cells confers effective resistance to the cotton wilt disease pathogen Verticillium dahliae. Mol Plant. 2016a;9(6):939-42. https://doi. org/10.1016/j.molp.2016.02.008.

Zhang T, Zhao YL, Zhao JH, et al. Cotton plants export microRNAs to inhibit virulence gene expression in a fungal pathogen. Nat Plants. 2016b;2(10):16153. https://doi.org/10.1038/nplants.2016.153.

Zhang Y, Wang XF, Ding ZG, et al. Transcriptome profiling of Gossypium barbadense inoculated with Verticillium dahliae provides a resource for cotton improvement. BMC Genom. 2013;14(1):637. https://doi.org/10. 1186/1471-2164-14-637.

Zhao Y, Wang H, Chen W, et al. Regional association analysis-based fine mapping of three clustered QTL for verticillium wilt resistance in cotton (G. hirsutum. L). BMC Genom. 2017;18(1):661. https://doi.org/10.1186/ s1 2864-017-4074-y.

Zhao J, Liu J, Xu J, et al. Quantitative trait locus mapping and candidate gene analysis for Verticillium wilt resistance using Gossypium barbadense chromosomal segment introgressed line. Front Plant Sci. 2018;9:682. https:// doi.org/10.3389/fpls.2018.00682.

Zhao Y, Chen W, Cui Y, et al. Detection of candidate genes and development of KASP markers for Verticillium wilt resistance by combining genomewide association study, QTL-seq and transcriptome sequencing in cotton. Theor Appl Genet. 2021;134(4):1063-81. https://doi.org/10.1007/ s00122-020-03752-4.

Zhu HQ, Feng ZL, Li ZF, et al. Characterization of two fungal isolates from cotton and evaluation of their potential for biocontrol of Verticillium wilt of cotton. J Phytopathol. 2013;161(2):70-7. https://doi.org/10.1111/jph. 12027. 